\title{
Valve with exchangeable biologic leaflets
}

\author{
Adrian Ebner, MD, ${ }^{\mathrm{a}}$ Geoffrey K.-G. Svensson, ${ }^{\mathrm{b}}$ W. Randolph Chitwood, MD, ${ }^{\mathrm{c}}$ Joseph F. Sabik III MD, ${ }^{\mathrm{b}}$ and \\ Lars G. Svensson, MD, PhD, ${ }^{\mathrm{b}}$ Asunción, Paraguay, Cleveland, Ohio, and Greenville, NC
}

There has long been a need for a biologic valve that is easy to insert, safe, and durable, with low transvalvular pressure gradients and no anticoagulation requirement. ${ }^{1}$ Despite recent advances in biologic valve leaflet treatments with glutaraldehyde, alcohol, ethylene, and surfactant, biologic valves are not routinely recommended-particularly for younger patients—-because of the risk of valve leaflet failure with time. ${ }^{1}$ This report describes a valve with an easy-toinsert base and exchangeable biologic leaflet set with low pressure gradients to allow the easier replacement of leaflets.

\section{MATERIALS AND METHODS}

The 2-part valve consists of a stiff, low-profile polymer base, 3 commissure attachment posts, and a polyester sewing cuff for intra-annular or supra-annular attachment. An engineering drawing of the 2-part valve frame is shown in Figure 1. The leaflets are composed of 3 laser-cut, mechanically matched pericardial leaflets attached to a flexible polymer ring, with commissures attached to the base posts. The leaflet pericardium is treated with ethanol and surfactants.

This valve's base and leaflet set were designed to replicate a $23-\mathrm{mm}$ supra-annular valve. Designs were tested and refined until the valve demonstrated lower gradients, larger comparative orifice area (effective orifice area), and better long-term pulse duplicator durability than commercially available valves. Hydrodynamic testing showed that the valve exceeded both CE Mark and Food and Drug Administration requirements for biologic valves (survived 200 million cycles at double the required closing pressure, ejected more than $96 \%$ of forward flow, had greater effective orifice area for size and lower pressure gradients).

The trial to test the new valve in patients was approved by The Italian Hospital Ethics Committee at Asunción and the Paraguay Ministry of Health. Three male patients with aortic valve stenosis (aged 49,62, and 72 years) were screened by preoperative transthoracic echocardiography, had consent obtained, and were scheduled for the implant procedure. The first 2 patients had bicuspid valves, and the third had senile degeneration of a trileaflet valve. Preoperative peak and mean gradients and areas were $110 / 72 \mathrm{~mm} \mathrm{Hg}$ and $0.66 \mathrm{~cm}^{2} ; 47 / 23 \mathrm{~mm} \mathrm{Hg}$ and $0.85 \mathrm{~cm}^{2}$; and $135 / 88 \mathrm{~mm} \mathrm{Hg}$ and $0.43 \mathrm{~cm}^{2}$.

Standard aortic valve replacement technique was used, with cardiopulmonary bypass, cardioplegia, "hockey stick" incision, and annular preparation. Two of the new valves were inserted with infra-annular sutures, and the

\footnotetext{
From the French Hospital, ${ }^{\mathrm{a}}$ Asunción, Paraguay; the Department of Thoracic and Cardiovascular Surgery, ${ }^{\mathrm{b}}$ Heart and Vascular Institute, Cleveland Clinic, Cleveland, Ohio; and the Department of Cardiovascular Sciences, ${ }^{c}$ Brody School of Medicine, East Carolina University, Greenville, NC.

Disclosures: Authors have a financial relationship with ValveXchange, Inc.

Received for publication Jan 19, 2012; accepted for publication Jan 25, 2012; available ahead of print Feb 20, 2012.

Address for reprints: Lars G. Svensson, MD, PhD, Department of Thoracic and Cardiovascular Surgery, Cleveland Clinic, 9500 Euclid Ave, J4-1, Cleveland, OH 44195 (E-mail: svenssl@ ccf.org).

J Thorac Cardiovasc Surg 2012;144:e13-4

$0022-5223 / \$ 36.00$

Copyright (c) 2012 by The American Association for Thoracic Surgery http://dx.doi.org/10.1016/j.jtcvs.2012.01.074
}

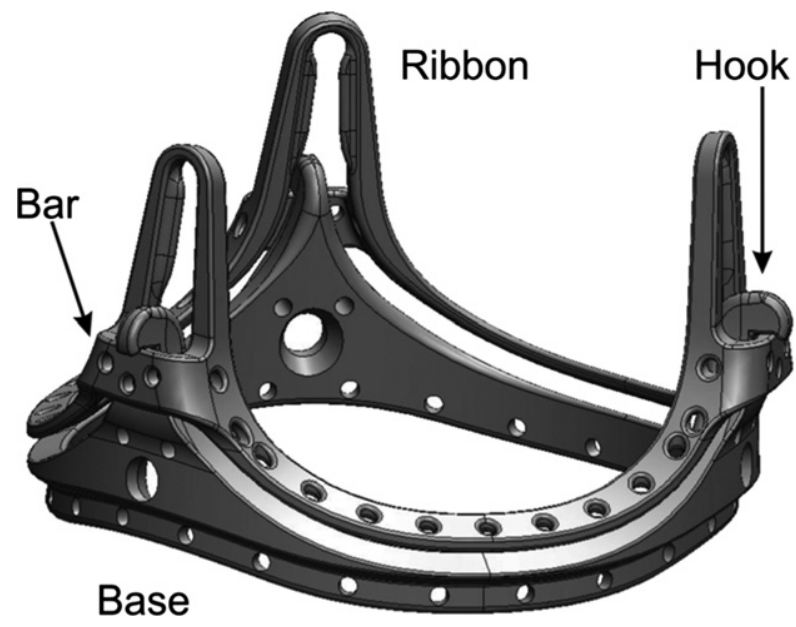

FIGURE 1. The design of the valve incorporates (1) flexible stent posts, (2) a well-controlled central gap, (3) precise stent circularity, and (4) $120^{\circ}$ leaflet symmetry. The base and ribbon that support the leaflets are fabricated from polyaryletherketone, a hard, fatigue-resistant medical-grade polymer. The ribbon is held in place by bars that lock underneath hooks on the base. Pericardial leaflets fill the gap between the ribbon and the base. These leaflets are under some compression and act as a gasket to prevent any leakage between the 2 mating components during valve function. The base component is rigid to prevent deformation.

third was inserted with supra-annular sutures. After placement through the native annulus, the sutures were passed through the sewing ring of the valve base and tied in a standard fashion. Three clear plastic shields protected the hooks on the approximately 6-mm tall stent posts (Figure 2). This valve's shorter stent posts and protective shields made tying the sutures easier than with conventional biologic valves with taller posts. The leaflets did not obstruct or hinder inspection after valve insertion, and additional valve sutures were easily placed in each patient (for annular frailty, a broken suture, and an "air knot"). Once the base was secured, the leaflet set was clipped into position, tested for strength of attachment, and internally inspected for proper mating with no gaps. After aortic closure, transesophageal echocardiography was repeated. Patients were weaned from cardiopulmonary bypass, and closure was performed in the standard fashion.

\section{RESULTS}

Intraoperative transesophageal echocardiography showed no aortic valve or perivalvular regurgitation. Peak and mean gradients were $18 / 7 \mathrm{~mm} \mathrm{Hg}, 14 / 7 \mathrm{~mm} \mathrm{Hg}$, and $17.3 / 7.5 \mathrm{~mm}$ Hg. Leaflet attachment took 3 to 6 minutes. All 3 patients survived the procedure, with no strokes and no blood transfusions. Thirty-day echocardiograms showed mean gradients of $19 \mathrm{~mm} \mathrm{Hg}, 8 \mathrm{~mm} \mathrm{Hg}$, and $11 \mathrm{~mm} \mathrm{Hg}$. Effective orifice areas were $1.87 \mathrm{~cm}^{2}, 1.79 \mathrm{~cm}^{2}$, and $1.6 \mathrm{~cm}^{2}$. One patient had mild to moderate perivalvular regurgitation. There was no intravalvular regurgitation. Ninety-day echocardiograms showed mean gradients of $3.6 \mathrm{~mm} \mathrm{Hg}, 2.2$ 


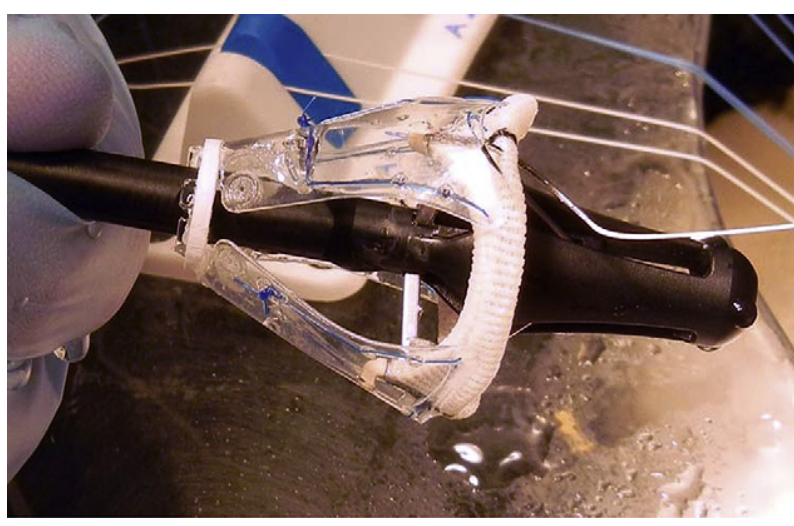

FIGURE 2. The valve base includes 3 clear, pliable shields that cover the hooks and prevent the sutures from tangling during insertion. These shields also act as soft tissue retractors to facilitate greater exposure and visualization during attachment of the leaflet set.

$\mathrm{mm} \mathrm{Hg}$, and $2.0 \mathrm{~mm} \mathrm{Hg}$. Effective orifice areas at that time were $1.35 \mathrm{~cm}^{2}, 1.74 \mathrm{~cm}^{2}$, and $1.35 \mathrm{~cm}^{2}$. At 90 days of follow-up, all 3 patients were symptom free.

\section{DISCUSSION}

One other report has described an easy-to-insert valve with separate components for insertion and removal. ${ }^{2}$ In our 3-patient cohort, the valve was easy to insert, and the shields protecting the stent posts facilitated suture tying. The valve's leaflets did not obstruct inspection and placement of additional sutures. Overall valve performance was excellent.

Safety and durability should be assessed in a larger series of patients. Valve replacement through a transapical approach is currently being investigated, and a working engineering model shows that a transapical approach and leaflet set exchange may be possible.

\section{References}

1. Svensson LG, Blackstone EH, Cosgrove DM 3rd. Surgical options in young adults with aortic valve disease. Curr Probl Cardiol. 2003;28:417-80.

2. Fernandez J, Gonzalez-Lavin L, Maranhao V, Yang SS. A new bioprosthesis for aortic and mitral valve replacement: preliminary evaluation of the Tascon valve. Tex Heart Inst J. 1987;14:31-8.

\title{
Giant vein graft pseudoaneurysm with pulmonary hemorrhage
}

\author{
Zain Khalpey, MD, PhD, MRCS, ${ }^{a}$ Edo Bedzra, MS, ${ }^{\mathrm{b}}$ Michael H. Stella, MD, ${ }^{\mathrm{c}}$ and Patrick O. Myers, MD, ${ }^{\mathrm{a}}$ \\ Boston, Mass
}

Saphenous vein graft (SVG) aneurysms, especially giant ones with severe dilatation, are rare and present with nonspecific symptoms. They occur about 1 decade after surgery and can be life-threatening, with an in-hospital mortality of $15.7 \% .^{1}$ Covered stents have been increasingly used for aneurysm treatment instead of classic surgical excision. ${ }^{2}$ The success of the intervention is time dependent. We report a death from multisystem failure after delayed SVG aneurysm exclusion using covered stent grafts.

\footnotetext{
From the Divisions of Cardiac Surgery ${ }^{\mathrm{a}}$ and Radiology, ${ }^{\mathrm{c}}$ Brigham and Women's Hospital, Harvard Medical School, Boston, Mass; and Harvard Medical School, ${ }^{\mathrm{b}}$ Boston, Mass.

Disclosures: Authors have nothing to disclose with regard to commercial support. Received for publication March 13, 2012; revisions received April 10, 2012; accepted for publication May 7, 2012; available ahead of print June 4, 2012.

Address for reprints: Patrick O. Myers, MD, Division of Cardiac Surgery, Brigham and Women's Hospital, Harvard Medical School, 75 Francis St, Boston, MA 02115 (E-mail: pmyers1@ partners.org).

J Thorac Cardiovasc Surg 2012;144:e14-6

0022-5223/\$36.00

Copyright (C) 2012 by The American Association for Thoracic Surgery

http://dx.doi.org/10.1016/j.jtcvs.2012.05.001
}

\section{CASE REPORT}

An 83-year-old man, who had previously undergone coronary artery bypass grafting 3 decades earlier, underwent a reoperation for a failed circumflex graft, a stenotic posterior descending artery graft, and aortic valve replacement for aortic stenosis. His left anterior descending (LAD) SVG was satisfactory at the time. Three years later, he underwent repeat cardiac catheterization at another institution that showed a $100 \%$ ostial lesion of the LAD and a $70 \%$ lesion proximal to the distal LAD anastomosis. A heparin-coated stent was deployed for a $100 \%$ ostial lesion in the right coronary artery. No particularities were noted regarding the SVG. This was complicated by progressive congestive heart failure, with the ejection fraction reduced to $35 \%$.

The patient developed hemoptysis, was diagnosed with bronchitis and bronchiectasis, and was treated with bronchodilators and antibiotics. He did not have another episode until 4 months later, when he presented with massive hemoptysis. He remained hemodynamically stable during the transfer to our institution and denied shortness of breath or chest pain. Bronchoscopy showed bleeding in the airway, with right-sided bleeding greater 